\title{
PERCEPÇÃO CROMÁTICA DE AMBIENTES DE TRABALHO DE ESCRITÓRIO
}

\section{CHROMATIC PERCEPTION OF OFFICE WORK ENVIRONMENTS}

\author{
Manuela Mello Fernandes ${ }^{1}$, M.Sc. \\ manuelafernandes02@gmail.com \\ Lourival Costa Filho' ${ }^{2}$, D.Sc. \\ lourival.costa@ufpe.br
}

\begin{abstract}
${ }^{1}$ Universidade Federal de Pernambuco - UFPE (PPGdesign), Recife, Brasil
${ }^{2}$ Universidade Federal de Pernambuco - UFPE (Curso de Design / PPGdesign e PPergo), Caruaru / Recife, Brasil
\end{abstract}

ambientes de trabalho de escritório, qualidade cromática percebida, Estética Ambiental, Ergonomia do Ambiente Construído

Buscando associar conhecimentos da Estética Ambiental à Ergonomia do Ambiente Construído, em prol de diretrizes que auxiliem o projeto da cor em ambiente de trabalho, este artigo apresenta uma pesquisa cujo objetivo foi avaliar a qualidade cromática percebida em ambientes de trabalho de escritório. Para tal, tomou as características de coerência (obtida pela redução do contraste) e de complexidade para estudo. A investigação empírica, estruturada através da Teoria das Facetas, utilizou o Sistema de Classificações Múltiplas para coletar os dados com 49 especialistas e 49 não especialistas em projetos de ambientes, analisados pela técnica de escalonamento multidimensional Análise da Estrutura de Similaridade, contando com o auxílio do programa computacional HUDAP (Hebrew University Data Analysis Package). Os resultados empíricos mostraram que o ambiente de trabalho de escritório com contraste médio (coerência média) e complexidade moderada está relacionado à qualidade cromática percebida, além de existir consenso parcial desses resultados entre os dois grupos abordados.

office work environments, perceived chromatic quality, Environmental Aesthetics, Ergonomics of the Built Environment

Seeking to relate knowledge from Environmental Aesthetics to the Ergonomics of the Built Environment, and being in favor of project guidelines that consider color in office environments, this article presents a research which aimed at evaluating the perceived chromatic quality in office work environments. To this end, it took into account the characteristics of coherence (achieved through reductions in contrast) and complexity. The empirical investigation, designed using Facet Theory, employed the Multiple Sorting Procedure to collect data from 49 specialists and 49 nonspecialists in environmental design, which was then analyzed using the multidimensional Similarity Structure Analysis (SSA), with the aid of the computer program HUDAP (Hebrew University Data Analysis Package). The empirical results showed that an office workspace with medium contrast (medium coherence) and moderate complexity is related to perceived chromatic quality. In addition, the results revealed a partial consensus among the social groups addressed. 


\section{Introdução}

A pesquisa apresentada aborda a qualidade cromática percebida em ambientes de trabalho de escritório, e partiu do pressuposto de que a escolha da cor para esses locais geralmente deixa para trás as avaliações empíricas de seus usuários frequentes, que dispensam longos períodos de tempo nesses espaços, a fim de cumprirem uma jornada que atenda às demandas da produção e da organização.

Há, portanto, o risco de se projetar os espaços utilizando a cor de maneira randômica, pois, quase sempre, os projetistas (designers e arquitetos) de interiores pensam na cor apenas como um elemento criativo e utilizamna de forma intuitiva, hipotética ou estereotipada.

Em ambientes de trabalho de escritório, essa decisão tem sido muito baseada no gosto dos que decidem e/ou realizam o planejamento cromático, no modismo, na facilidade de manutenção ou até mesmo nas cores da identidade coorporativa da empresa, sem maiores preocupações com a tarefa que será desempenhada, ou mesmo como a cor pode afetar os usuários dos ambientes tanto psicológica como fisiologicamente (FERNANDES; COSTA FILHO, 2018), muito embora, para Mahnke (1996), a cor - pelo fato de ser um elemento que atua como estímulo visual, impacta na condição de prazer e de bem-estar - não pode ficar atrelada apenas a uma questão do gosto pessoal dos que decidem e/ou projetam os espaços interiores.

De acordo com a visão de Figueiredo e Mont'Alvão (2004), o projeto cromático deve ser adequado a um propósito determinado e considerar três pontos importantes: 1) deve estar de acordo com a função do espaço e com as tarefas que lá serão desempenhadas; 2) deve evitar que o ambiente se torne extremamente estimulante ou igualmente depressivo; 3) não deve criar efeitos fisiológicos e psicológicos negativos.

Mahnke (1996) apurou que a cor tem grande impacto nas reações psicológicas e no bem-estar fisiológico, podendo afetar o ser humano em bases tanto visuais como não visuais. Por isso, a resposta humana para a cor, segundo esse autor, é total, já que influencia o indivíduo tanto psicológica como fisiologicamente.

A partir dessas influências, é possível afirmar ainda, apoiando-se na visão de Figueiredo e Mont'Alvão (2006), que a cor pode ser utilizada para auxiliar usuários frequentes de ambientes de trabalho de escritório a se sentirem física e psicologicamente confortáveis, atuando, positiva ou negativamente, no seu desempenho e comportamento. Logo, as interações humanas com a cor no ambiente podem influenciar o comportamento, interferir diretamente na melhoria da produtividade e, principalmente, na saúde desses usuários.

Abordar a qualidade cromática em ambientes de trabalho de escritório - no âmbito da ergonomia -, visando à obtenção de dados que possam auxiliar o planejamento da cor nos elementos desses espaços, requer a cumplicidade da área destacada com outros campos do saber, que subsidiem, por exemplo, sugestões teóricas e métodos de análise de aspectos psicológicos para identificar e compreender esse tipo de avaliação.

Destarte, julgou-se, dentro dessa perspectiva, ser importante a associação da Estética Ambiental à Ergonomia do Ambiente Construído, pelo interesse de ambas no modo como as pessoas percebem e tomam decisões nos ambientes, em prol de diretrizes de projeto que potencializem a interação humano-ambiente.

A Estética Ambiental - que representa a fusão de duas áreas de investigação: a psicologia ambiental e a estética empírica - pode auxiliar a Ergonomia do Ambiente Construído com teorias, evidências empíricas e aplicações metodológicas, para tentar explicar o estímulo físico e a resposta humana, além de como traduzir esse entendimento em um projeto de ambiente julgado favoravelmente pelo usuário.

Essa aproximação favorece a avaliação da qualidade cromática percebida em ambientes de trabalho de escritório que, por conseguinte, pode revelar bases para o planejamento cromático desses espaços, além de, mais amplamente, contribuir para a melhoria das interações humano-ambiente. 
Dessa forma, a qualidade cromática percebida em ambientes de trabalho influencia a maneira como os espaços são vivenciados. Corroborando com esse raciocínio, de acordo com a visão de Nasar (2000), o caráter visual do ambiente tem importantes impactos na experiência humana. Pode evocar fortes emoções como prazer e medo, atuar como estressor ou restaurador e induzir inferências sobre lugares e pessoas. Pode também influenciar o comportamento, levando pessoas a evitar ou ir a determinados lugares.

Para estruturar o nível teórico desta pesquisa, partiu-se de uma teoria defendida por Kaplan e Kaplan (1982), que estendeu a ideia de Gibson (1979) de affordances perceptuais no ambiente, argumentando a favor de recursos cognitivos que, embora relacionados à sobrevivência, requerem processamento de informações. Para eles há uma predisposição dos seres humanos por ambientes que ofereçam envolvimento e possam fazer sentido. Para ser preferido, nesse contexto, o ambiente precisaria produzir envolvimento para atrair a atenção das pessoas, assim como fazer sentido, para poder se tornar legível e compreendido por elas. Os autores acrescentam que o "envolvimento" estaria relacionado com a complexidade da cena; enquanto o "fazer sentido" com a sua coerência, legibilidade, compreensão ou entendimento.

Pautando-se na teoria dos Kaplans acima mencionada, essas duas características preditoras da preferência humana por ambientes - coerência e complexidade - foram tomadas para estudo nesta pesquisa pelas suas prováveis influências na qualidade cromática percebida.

A avaliação da qualidade cromática percebida, no âmbito da ergonomia, demanda a associação das cores dos ambientes de trabalho em escritório, com a experiência das pessoas em estar e permanecer nesses locais, condição que foi tratada nesta pesquisa como uma expressão desse tipo de qualidade.

A partir dessa relação, admitiu-se a possibilidade de especialistas em projetos de ambientes avaliarem esses espaços de modo diferente de os não especialistas no assunto. Sobre essa distinção, Nasar (2008) apurou que esses profissionais veem significados diferentes para as mesmas características ambientais. O mesmo autor ainda alerta que essas diferenças se refletem no planejamento dos espaços, na medida em que podem resultar em soluções pouco atraentes para o público.

Assim, as inadequações citadas assumem maior importância por causa da relevância do significado de ambientes de trabalho em escritório, e da resposta avaliativa no comportamento da população usuária. Por essa razão, esta pesquisa considerou que especialistas em projeto de ambientes se constituem grupo à parte em relação à aparência desejada de ambientes, inclusive com visão particular sobre a sua qualidade cromática percebida, distinta daquela do usuário não especialista.

Para finalizar essa Introdução, cabe ainda destacar que a investigação empírica realizada foi delineada de acordo com a Teoria das Facetas - procedimento de pesquisa criado e desenvolvido por Louis Guttman, durante os anos cinquenta, do século passado -, visando à possibilidade de permitir relacionar sistematicamente o delineamento da pesquisa, o registro dos dados e a sua análise estatística, para operacionalizar o objetivo de "avaliar a qualidade cromática percebida em ambientes de trabalho de escritório, em prol de diretrizes para o planejamento da cor desses locais".

A seguir, no próximo item, será delineada a abordagem teórica sobre a Ergonomia do Ambiente Construído e a Estética Ambiental, na medida em que vai se discutindo evidências empíricas sobre a qualidade cromática percebida em ambientes. 


\section{Considerações Teóricas}

A Ergonomia do Ambiente Construído é uma disciplina científica preocupada com as interações humanoambiente, interessada em contribuir de modo aprofundado com pesquisas sobre a melhoria do projeto do espaço de atividade, visando à adaptação e à conformação do meio construído às diversas necessidades de seus ocupantes.

Para Bins Ely, Olinto e Villela (2016), a interação entre o ambiente, o usuário e a atividade, bem como os aspectos da percepção ambiental vêm sendo estudados pela Ergonomia do Ambiente Construído.

Villarouco (2011; 2018), contudo, tem afirmado que a Ergonomia do Ambiente Construído extrapola as questões puramente arquitetônicas, focando seu posicionamento na adaptabilidade e conformidade do espaço às tarefas e atividades que nele serão realizadas. Evocando, nas suas abordagens, além do conforto ambiental e da acessibilidade integral, a percepção ambiental, assim como a adequação de materiais (como cores e texturas), sendo necessária que essa abordagem seja sistêmica, para visualizar a situação como um todo e não em partes isoladas.

Levando em conta essa abordagem sistêmica da Ergonomia do Ambiente Construído, que considera o ambiente como um todo e não em partes isoladas, esta pesquisa teve o cuidado de tomar para estudo duas variáveis - coerência e complexidade - que representam características visuais relacionadas com todos os elementos ambientais do meio construído, ou seja, que possibilita a abordagem sistêmica do ambiente.

Como quaisquer outros, os ambientes de trabalho também influenciam os usuários, afetando os custos de produção, a eficiência do processo, e o estado de ânimo, ao fim de cada jornada de trabalho. Quando mal projetados, esses tipos de espaços podem influir na saúde do trabalhador de maneira negativa; enquanto o oposto pode motivar e melhorar as condições de saúde, reduzindo a fadiga e o estresse gerado no desempenho das atividades físicas e cognitivas (COSTA; ANDRETO; VILLAROUCO, 2011).

Isso significa que, a fim de minimizar erros e evitar a monotonia, os ambientes de trabalho de escritório precisam de elementos ambientais - como por exemplo a cor - que promovam estímulos, gerem interesse e desencadeiem motivação, e bem-estar na medida certa, aos usuários desses espaços.

Pesquisas recentes - acerca da cor - apuraram haver fortes evidências de que, nos ambientes de trabalho, a cor desempenha papel significativo na percepção e no comportamento humano. Sob esse aspecto, a utilização da cor nesses locais pode contribuir para a sensação de bem-estar, beneficiando o público usuário na realização de suas atividades (SAVAVIBOOL, 2016; OZTURK, 2010).

Levando em conta que, muitas vezes, os projetos de ambientes são decisões de especialistas, seria interessante que esses especialistas e usuários dos espaços compartilhassem valores estéticos comuns, ou que, ao menos, conforme explica Costa Filho (2012), tais especialistas pudessem avaliar as necessidades estéticas do público usuário nessa fase. Dessa forma, a confiança nas decisões desses profissionais poderia ser aceita, evitando que as concepções prestassem um desserviço ao público usuário do futuro.

Estudar os efeitos da cor em ambientes de trabalho de escritório, no âmbito da Ergonomia do Ambiente Construído, requer considerar as condições visuais, ou seja, avaliar a qualidade cromática percebida, a fim de se obter diretrizes para auxiliar um projeto cromático funcional, que traga o benefício de se oferecer ambientes de trabalho adequados aos seus usuários frequentes.

Apoiando-se em uma definição de Nasar (1988) para a qualidade visual percebida, pode-se afirmar que a qualidade cromática percebida seria um constructo psicológico, portanto subjetivo, que envolve referências primárias para a cor no ambiente (como mensurar a variedade ou a coloração de uma cena) ou para os sentimentos das pessoas sobre a cor no ambiente observado (como mensurar a emoção ou a tranquilidade promovida pela cor de uma cena). As primeiras são julgamentos perceptuais/ cognitivos, enfocados nesta 
pesquisa; enquanto as segundas são julgamentos emocionais ou afetivos.

De acordo com Nasar (2008), a aparência e o significado do ambiente podem aumentar a carga sensorial, o medo e o estresse. Em sentido inverso, ao criar ou melhorar esses aspectos, pode-se, por consequência, proporcionar uma série de benefícios para os usuários e se obter uma resposta favorável, se um número expressivo de pessoas assim acharem.

Para avaliar os julgamentos perceptuais/cognitivos, relacionados à qualidade cromática percebida em ambientes de trabalho de escritório, como dito na Introdução, foram tomadas duas características ambientais notáveis para esse tipo de avaliação - coerência e complexidade - a fim de que, na fase metodológica, testar se, de fato, elas são aderentes para esse propósito e os seus efeitos no tipo de avaliação enfocada nesta pesquisa. Os próximos parágrafos apresentam evidências empíricas sobre essas duas características. A coerência - que representa uma variável de ordem - está relacionada à preferência ambiental por atender à necessidade humana do ambiente "fazer sentido" (KAPLAN; KAPLAN, 1982), mas, devido ao seu caráter altamente subjetivo, ela será considerada nesta pesquisa, através de uma variável relacionada, o contraste, na medida em que a redução desse elemento na cena eleva a coerência percebida, que, por sua vez, reduz a incerteza, aumenta o tom hedônico (agradabilidade e beleza) e a compreensão (NASAR, 2008). A partir dessa lógica, contraste baixo produziria coerência alta; enquanto contraste alto, ao contrário, promoveria coerência baixa, que dificultaria a compreensão do ambiente.

Por definição, a complexidade (variação e quantidade de elementos na cena) cria incerteza, que, por isso, provoca o envolvimento para reduzir a incerteza (BERLYNE,1972; WOHLWILL, 1976). Essa relação entre a complexidade e o interesse (despertar da incerteza), portanto, deve ser direta e monotônica. Por outro lado, o tom hedônico (beleza ou agradabilidade) foi postulado como tendo uma relação em forma de "U" invertido (não monotônico) com a complexidade. Com o aumento da complexidade, esse efeito deve aumentar até um ponto - um nível ideal de excitação - após o qual diminui. Logo, a complexidade mínima provavelmente seria monótona e entediante; a máxima seria caótica e estressante (BERLYNE,1972; WOHLWILL, 1976;); e a moderada parece ser o nível mais agradável, ou ideal (NASAR, 2008).

De acordo com Nasar (1988), os achados empíricos para a coerência (obtida através da redução do contraste), em relação a sua possibilidade de reduzir a incerteza e aumentar o tom hedônico, vem sendo consistentemente corroborados nas pesquisas, ocorrendo o oposto em relação à complexidade, talvez por causa dos procedimentos metodológicos, ou da falta de utilização de uma gama suficiente de complexidade para desacelerar a agradabilidade que emerge.

A informação acima, sobre a consistência dos achados para a coerência (obtida pela redução do contraste), mostra-se inconsistente em relação aos achados iniciais de Costa Filho (2012), e também em outras investigações realizadas sob sua orientação (SILVA JÚNIOR, 2017; OLIVEIRA, 2018; AMORIM, 2019), embora também corroborem com a informação da inconsistência da complexidade nas avaliações de lugares.

Antes de finalizar essas considerações teóricas, cabe ainda destacar que, apesar de as respostas avaliativas para a qualidade cromática percebida, por si só, não poderem prever o comportamento real do usuário, a avaliação combinada de respostas avaliativas e do comportamento previsto dá uma boa indicação do comportamento real (NASAR, 1988). Logo, nesta pesquisa, os participantes foram solicitados a avaliar em que medida várias cenas de ambientes de trabalho de escritório favoreciam estar e permanecer neles. 


\section{Considerações Teórico-Metodológicas}

Esta pesquisa adotou a Teoria das Facetas (SHYE; ELIZUR; HOFFMAN, 1994; BILSKY, 2003) no desenho de sua investigação empírica, apoiando-se também na "avaliação objetivada do lugar", proposta por Canter (1983), que considera as intenções e as ações das pessoas para a avaliação de lugares, como também recomenda a ergonomia do ambiente construído.

O uso da Teoria das Facetas (TF) envolve inicialmente a identificação dos diferentes conceitos que delineiam a pesquisa, que podem advir da literatura ou de explorações in loco. Essa etapa consiste em estabelecer hipóteses, encontrar as facetas e definir os elementos que as constituem.

Cada faceta representa uma categoria conceitual, constituída por subcategorias de elementos a serem pesquisados. O primeiro tipo de faceta (Faceta de População) define a população da pesquisa e os grupos de interesse. O segundo tipo (Facetas de Conteúdo) diz respeito ao conteúdo das variáveis investigadas. A faceta de conteúdo e a faceta de população representam o domínio da pesquisa. O terceiro tipo (Faceta de Racional) consiste no universo de possibilidade de respostas dos sujeitos, que é comum a todas as facetas (BILSKY, 1994).

Por definição, geralmente, há três tipos de facetas básicas para a avaliação de lugares, cada uma representando um componente do local a ser investigado: referente, foco, nível. O primeiro tipo, faceta de referente, define o referente da experiência e expõe os diferentes aspectos em que as pessoas se baseiam para realizar suas avaliações. $\mathrm{O}$ segundo tipo, faceta de foco, modula o referente da experiência. $\mathrm{O}$ terceiro tipo, faceta de nível, leva em conta a existência da escala ambiental, que influi na avaliação dos espaços.

Essas relações - entre os diversos aspectos da experiência das pessoas com um determinado ambiente podem ser sumarizadas através de uma sentença estruturadora, que descreve os componentes dos ambientes e a forma como são vivenciados pelos usuários durante seu uso.

O Quadro 1 representa a sentença estruturadora para a avaliação da qualidade cromática percebida em ambientes de trabalho de escritório, o nome de algumas facetas e os seus elementos de composição interna.

\begin{tabular}{|c|c|c|}
\hline \multicolumn{3}{|c|}{ A pessoa $x$ (especialista $\mid$ não especialista) avalia que o ambiente de trabalho de escritório com } \\
\hline $\begin{array}{l}\text { Faceta (a) - CONTRASTE } \\
\text { (a1) baixo } \\
\text { (a2) médio } \\
\text { (a3) alto }\end{array}$ & e & $\begin{array}{l}\text { Faceta (b) - COMPLEXIDADE } \\
\text { (b1) mínima } \\
\text { (b2) moderada } \\
\text { (b3) máxima }\end{array}$ \\
\hline $\begin{array}{l}\text { RACIONAL } \\
\text { (1) nada } \\
\text { (2) pouco } \\
\text { (3) mais ou menos } \\
\text { (4) muito } \\
\text { (5) demais }\end{array}$ & & $\begin{array}{l}\text { estar e permanecer trabalhando no local } \\
\text { (uma expressão da qualidade cromática percebida na cena) }\end{array}$ \\
\hline
\end{tabular}

Quadro 1: Sentença estruturadora para a avaliação da qualidade cromática percebida em ambientes de trabalho de escritório

Essa sentença estruturadora é um modelo conceitual para a avaliação da qualidade cromática percebida em ambientes de trabalho de escritório. $\mathrm{O}$ primeiro tipo de faceta se refere à população abordada. $\mathrm{O}$ segundo tipo de faceta abrange o conteúdo das variáveis pesquisadas e, juntamente com a faceta da população abordada, definem o domínio desta pesquisa. O terceiro tipo de faceta descreve o universo de respostas possíveis (racional comum a todas as facetas) em relação ao domínio da pesquisa.

A população que se propõe a avaliar nesta pesquisa é constituída por dois diferentes tipos de interesse nos ambientes de trabalho de escritório. No primeiro grupo, predomina o interesse de projetar os espaços e/ou os arranjos físicos do espaço de trabalho, sendo sua experiência - com esse tipo de espaço - marcada pelo 
conhecimento científico. No segundo grupo, há o interesse de realizar tarefas/atividades e a experiência com os ambientes é marcada pelo senso comum. Fazem parte desses grupos: 1| especialistas; 2 | não especialistas.

As facetas de conteúdo são formadas pelas duas (2) características ambientais tomadas como facetas de referentes da experiência, ou seja, o contraste e a complexidade da cor dos elementos ambientais.

A faceta (a), CONTRASTE, leva em conta o grau em que as cores se destacam nos atributos que compõem os ambientes de trabalho de escritório, e reúne, entre seus elementos internos, três diferentes níveis: (A1) baixo; (A2) médio; (A3) alto.

A faceta (b), COMPLEXIDADE, remete à variedade e a quantidade de atributos nos ambientes de trabalho de escritório, tendo como elementos internos três níveis: (B1) mínima; (B2) moderada; (B3) máxima.

Os elementos internos das duas facetas de conteúdo - contraste e complexidade - podem ser organizados de forma semelhante a uma análise combinatória, produzindo nove (9) conjuntos (A3 x B3 = AB9), que expressam as diferentes situações a serem consideradas na investigação empírica.

Foram desconsideradas facetas tanto de foco como de nível da experiência, na medida em que o foco já está expresso nos elementos internos das duas facetas de referente, e o nível da avaliação é geral, ou seja, recai em ambientes de trabalho em escritório.

A faceta de racional descreve as possíveis respostas da população em relação à qualidade cromática percebida em ambientes de trabalho de escritório, sistematizadas em uma escala "Likert" de cinco pontos: 1| nada; $2 \mid$ pouco; $3 \mid$ mais ou menos; $4 \mid$ muito; $5 \mid$ demais.

A sentença estruturadora para a avaliação proposta, como uma referência inicial desta pesquisa, é analisada em relação aos resultados empíricos e deve corroborar ou refutar as hipóteses levantadas de que as características de coerência (obtida pela redução do contraste) e de complexidade, bem como os níveis ordenados de seus elementos internos são aderentes, para a avaliação da qualidade cromática percebida em ambientes de trabalho em escritório. Assim, após a análise/interpretação dos dados, há informações suficientes para construir ou não uma nova sentença, a ser estruturada como consequência direta dos resultados empíricos apurados e, futuramente, colocada a teste.

\section{Considerações Metodológicas}

A investigação realizada, classifica-se como uma pesquisa de campo, do tipo exploratória, com amostragem não probabilística, ou seja, sem uma definição prévia do número de participantes ou do percentual de confiabilidade creditada aos dados coletados (MARCONI; LAKATOS, 2002).

Para coleta dos dados, foi utilizado o Sistema de Classificações Múltiplas (SCM), adaptado por Canter, Brown e Groat (1985), que consiste em pedir aos participantes para classificar os mesmos elementos diversas vezes, através de critérios por eles definidos (classificações livres) ou pelo pesquisador (classificações dirigidas), para entender suas ideias sobre o objeto estudado. As classificações consideram as similaridades, de modo que elementos de uma mesma categoria tenham algo distinto das demais. O SCM permite o uso de materiais visuais, recurso que reduz os riscos de apresentar questões tendenciosas (COSTA FILHO, 2014).

Na pesquisa, foi utilizado um conjunto de nove cenas (Figura 1), todas do Google Imagens, de acordo com a Sentença Estruturadora para a avaliação da qualidade cromática percebida em ambientes de escritório, usado como elementos de estímulo aos participantes. As cenas foram submetidas a um corpo de 10 juízes, alunos do PPGdesign/UFPE, buscando o consenso para os níveis de contraste e complexidade indicados. 


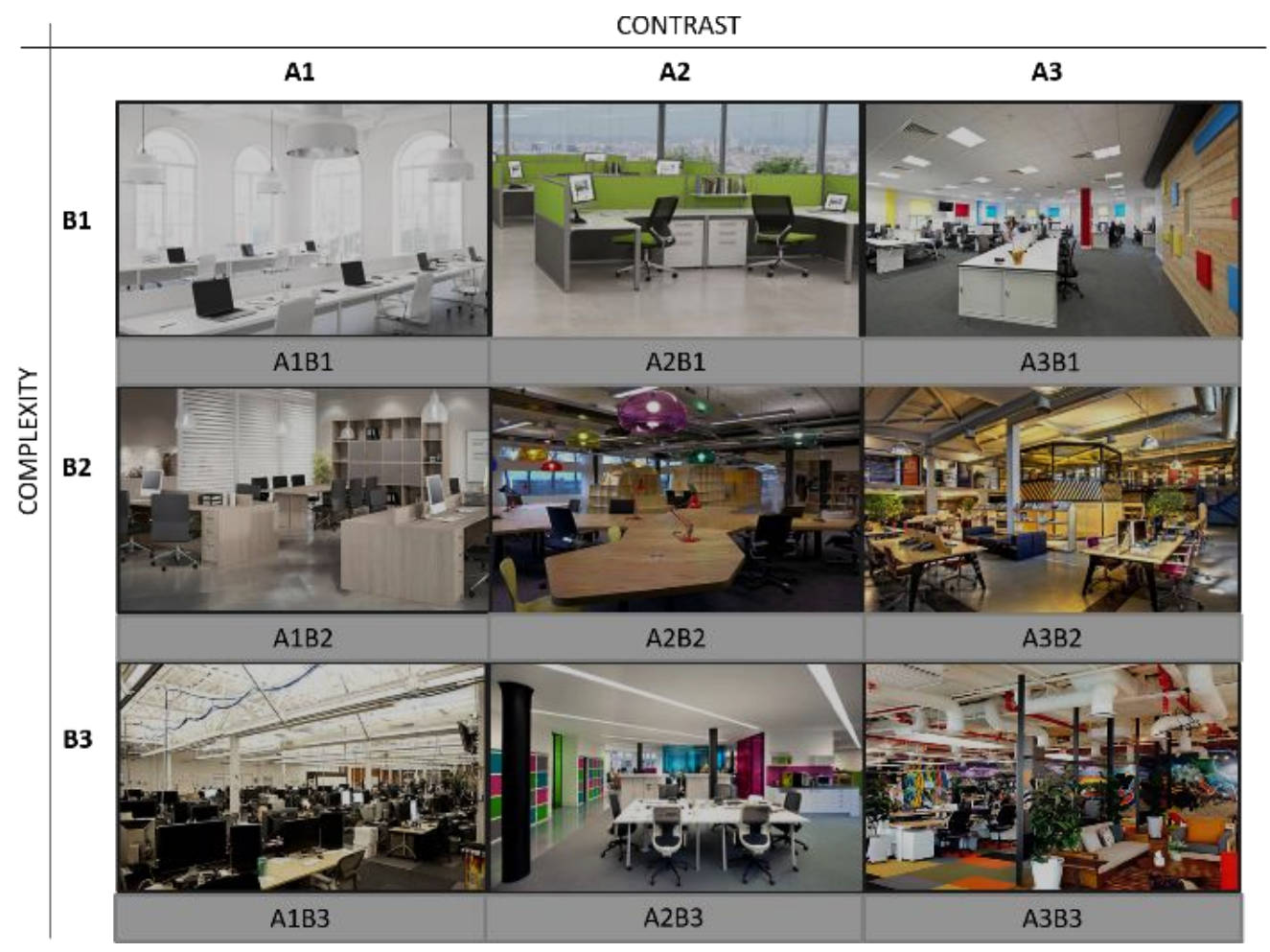

Figura 1: cenas representando as relações de contraste e de complexidade em ambientes de trabalho de escritório

Conforme apurado por Stamps (1992), quando se trata da avaliação da qualidade visual do ambiente, pode-se obter resultados muito confiáveis ao utilizar como elementos de estímulo fotografias coloridas, vídeos, slides, fotomontagens e simulações.

É importante informar que a coleta de dados ocorreu logo após a aprovação e licença do Comitê de Ética em Pesquisa Envolvendo Seres Humanos (CEP) da UFPE. Os objetivos da pesquisa e o processo de classificações dirigidas foram orientados aos voluntários, que preencheram o Termo de Consentimento Livre e Esclarecido (TCLE) caso aceitassem participar. Dessa forma, a pesquisa teve o seu caráter ético validado. As entrevistas foram todas agendadas previamente, realizadas de forma presencial com os dois grupos de participantes, solicitados a avaliar em que medida cada uma das cenas apresentadas favorecia estar e permanecer trabalhando no espaço (uma expressão da qualidade cromática percebida na cena). Após finalizadas, as classificações dirigidas foram registradas em um formulário especialmente desenvolvido.

Os dados obtidos foram analisados pela técnica de escalonamento multidimensional denominada Análise da Estrutura de Similaridade (Smilarity Structure Analysis - SSA), com o auxílio do programa informático HUDAP (Hebrew University Data Analysis Package), desenvolvido por Amar e Toledano (2005).

O SSA é uma técnica para análise de dados por similaridade, que fornece uma representação métrica de informações não métricas, com base nas distâncias relativas dentro de um conjunto de pontos (ROAZZI; MONTEIRO; RULLO, 2009). A proximidade das variáveis no espaço multidimensional da SSA é proporcional ao grau de correlação que apresentam. Essas relações de similaridades podem formar regiões de contiguidade, que possibilitam verificar se as hipóteses iniciais são transformadas em hipóteses regionais, em relação às quais se espera evidenciar regiões distintas que abarquem aos elementos internos de cada faceta.

As análises dos diagramas plotados pela SSA podem revelar padrões e dados implícitos nos resultados obtidos, imperceptíveis nas análises quantitativas usuais (BORG; LINGOES, 1987). 
De acordo com Costa Filho et al. (2016), as facetas têm papel específico na estruturação dos diagramas da SSA. Cada região é especificada para um dado subconjunto de variáveis no espaço da SSA, que as identifica através de um elemento interno comum de cada facetas da sentença estruturadora. Essas regiões tomam formas de separação muito específicas (padrões), como faixas paralelas (axial), configurações circulares (modular), ou angulares (polar) (Figura 2).

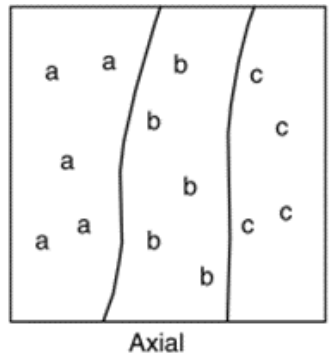

Figura 2: Tipos de sepa
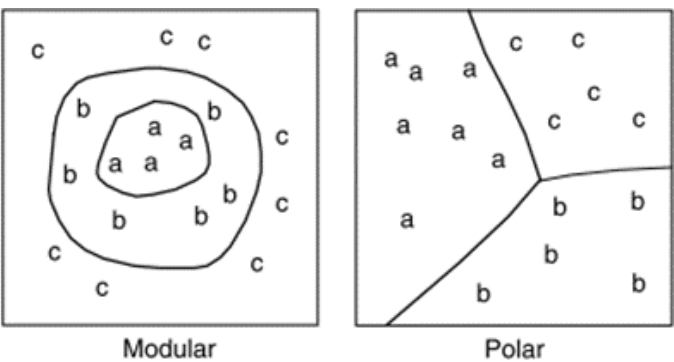

Polar

Fonte: Borg $(2005$, p. 598)

A forma de separação encontrada em uma análise multidimensional, segundo Bilsky (2003), depende da condição dessa ser resultante de facetas ordenadas, ou seja, aquela em que cada elemento interno denota maior grau do atributo em relação ao precedente.

Uma faceta ordenada pode desempenhar um papel axial ou modular ao dividir o diagrama da SSA, dependendo de sua relação com as outras facetas da sentença estruturadora. Se não tem relação com as demais facetas, apresentar-se-á como axial; já quando se encontra relacionada com uma ou mais facetas, seus elementos se manifestarão de forma modular. Além das facetas ordenadas, existe outra em que os elementos se diferenciam de modo qualitativo, mas sem qualquer ordem óbvia. Tais facetas têm um papel polar.

Caso as hipóteses regionais sejam verificadas, revelam aspectos relativamente estáveis do conceito investigado, dando-lhe legitimidade, além de confirmar a estrutura interna de conceitos e atributos, possibilitando a percepção de componentes empiricamente verificáveis e da forma como se inter-relacionam (SHYE; ELIZUR; HOFFMAN, 1994).

O SSA permite ainda testar e confirmar se um determinado grupo opera da mesma maneira que outro na avaliação enfocada. Para isso, é possível cadastrar os grupos de participantes como variáveis externas, que não interferem no resultado do diagrama ou mapa de componentes originais da SSA. Esse tipo de variável externa, segundo Monteiro e Roazzi (2009), é considerada um grande avanço na SSA, pois permite a integração de subpopulações no mapa de componentes originais, reduzindo o número de avaliações.

\section{Considerações Empíricas}

Ao final da coleta de dados, através de classificações dirigidas, ao todo, 98 sujeitos participaram da pesquisa, sendo 49 especialistas em projetos de ambientes (30 arquitetos, 17 designers, 2 com ambas formações) e 49 não especialistas, em sua maioria mulheres com idade entre 28 e 37 anos e curso superior completo.

A qualidade cromática percebida foi avaliada nesta pesquisa através dos efeitos da coerência (obtida pela redução de contraste) e da complexidade da cor dos ambientes de trabalho de escritórios.

Para testar as facetas no diagrama original da SSA - cada uma das nove cenas representadas graficamente por pontos nesse espaço euclidiano - receberam cores que indicam o seu pertencimento a um determinado elemento interno das facetas. Em seguida, foi analisada a existência ou não de padrões conhecidos na divisão do mapa da SSA, em regiões de contiguidade. 
Foi apurado que tanto a Faceta A (Figura 3) como a Faceta B (Figura 4 - página seguinte) formaram regiões de contiguidade, significando que são aderentes ou determinantes para a avaliação da qualidade cromática percebida em ambientes de trabalho de escritório.

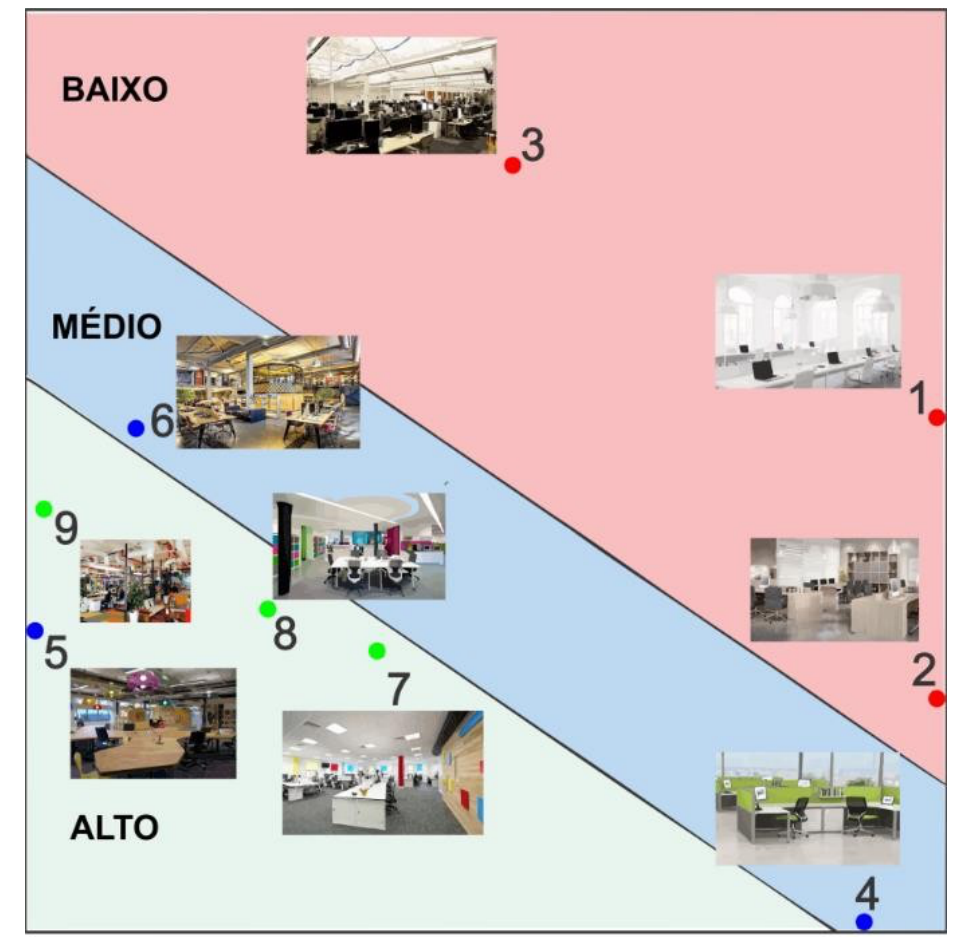

Figura 3: Diagrama da Faceta A (CONTRASTE).

Na Figura 3, o diagrama da Faceta A, CONTRASTE, mostra duas linhas inclinadas e paralelas, que dividem o espaço da SSA em três regiões de contiguidade numa ordem hierárquica - definida através dos escores das cenas nas classificações - que se inicia da faixa central (médio contraste), seguindo para a parte superior (baixo contraste) e, depois, inferior (alto contraste).

Essa faceta ordenada desempenha claramente um papel axial sobre o diagrama, e revela inexistir relação entre o contraste e a complexidade dos ambientes de trabalho em escritório na avaliação da qualidade cromática percebida e que os participantes conseguiram captar o contraste como uma característica aderente para a avaliação enfocada, além dos seus três diferentes níveis, corroborando com uma das hipótese da pesquisa, inicialmente definida na sentença estruturadora, e indicando que os participantes preferem ambientes de trabalho em escritório com contraste cromático médio (coerência cromática média).

Embora quase todas as cenas tenham sido captadas pelos participantes, de acordo com o nível de contraste previsto, a cena de número 5, de contraste médio, foi captada como tendo contraste alto, talvez devido ao formato irregular da mesa e tipo de luminárias. Essa única exceção, entretanto, não invalida os resultados.

Na Figura 4, o diagrama da Faceta B, COMPLEXIDADE, mostra duas linhas inclinadas e paralelas, como na Faceta A, que dividem o espaço do SSA em três regiões de contiguidade, numa ordem hierárquica que, pelos escores das cenas, começa na faixa central (complexidade moderada), segue para a faixa inferior do diagrama (complexidade mínima) e, depois, para a faixa superior (complexidade máxima). 


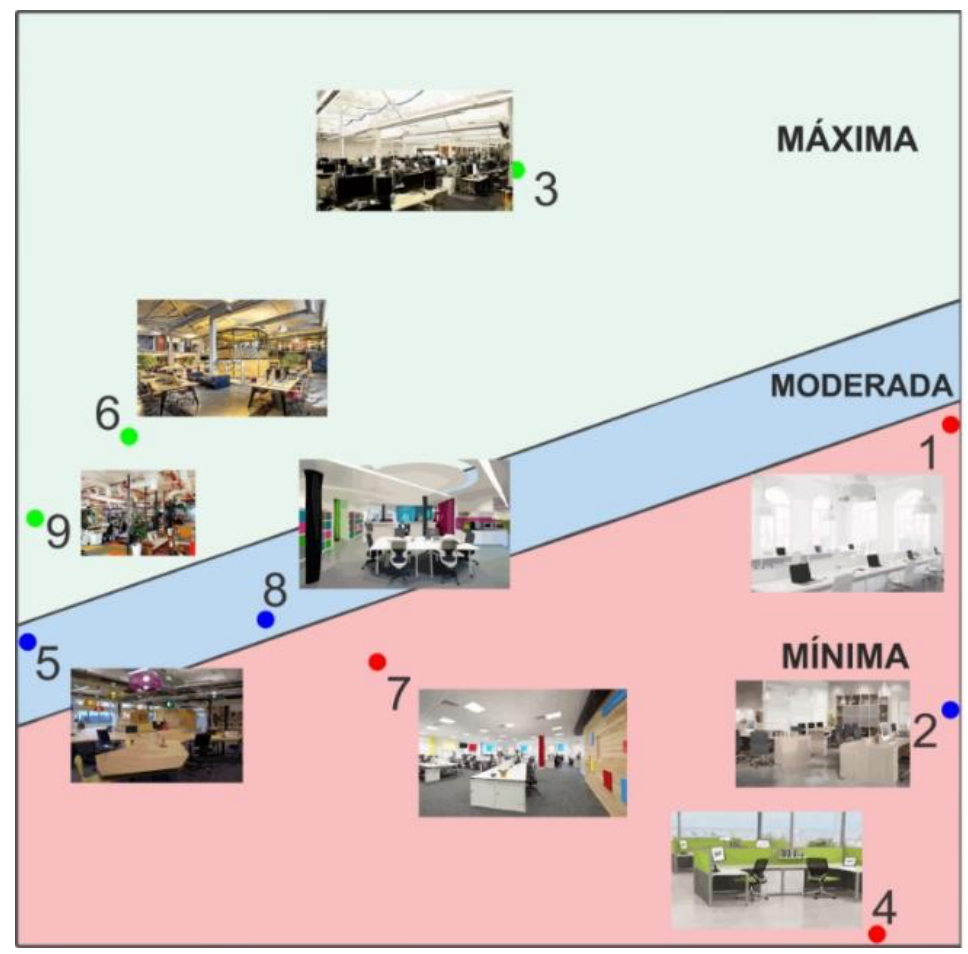

Figura 4: Diagrama da Faceta B (COMPLEXIDADE).

A Faceta B, igualmente ordenada, desempenha um papel axial no diagrama da SSA, revelando a inexistência de relação entre essa característica e aquela de contraste cromático, consideradas para a avaliação enfocada, e, também, que os participantes captaram a complexidade das cenas como uma característica aderente para a avaliação da qualidade cromática percebida em ambientes de trabalho em escritório, bem como seus três diferentes níveis, corroborando com outra hipótese da pesquisa, inicialmente definida na sentença estruturadora, evidenciando que os participantes abordados preferem ambientes de trabalho em escritório com complexidade cromática moderada, nesse caso, como sugere a teoria.

O diagrama da SSA para a complexidade mostra apenas uma exceção regional, a cena de número 2, com complexidade cromática moderada e percebida como mínima. Ao se observar a matriz de similaridade, a cena de número 2 tem alta correlação com a cena de número 1 , ambas com contraste cromático mínimo e de complexidade diferentes, levando a pensar que o contraste cromático foi o que norteou esse entendimento. Ao analisar os escores obtidos em cada cena - nas classificações dirigidas - nota-se que a cena com maior escore, portanto com mais qualidade cromática percebida (QCP), foi a de número 06 , com contraste médio (coerência média) e complexidade máxima; já o oposto recaiu na cena de número 03 , com contraste baixo (coerência alta) e complexidade máxima, segundo os entrevistados (Figura 5 - página seguinte). 


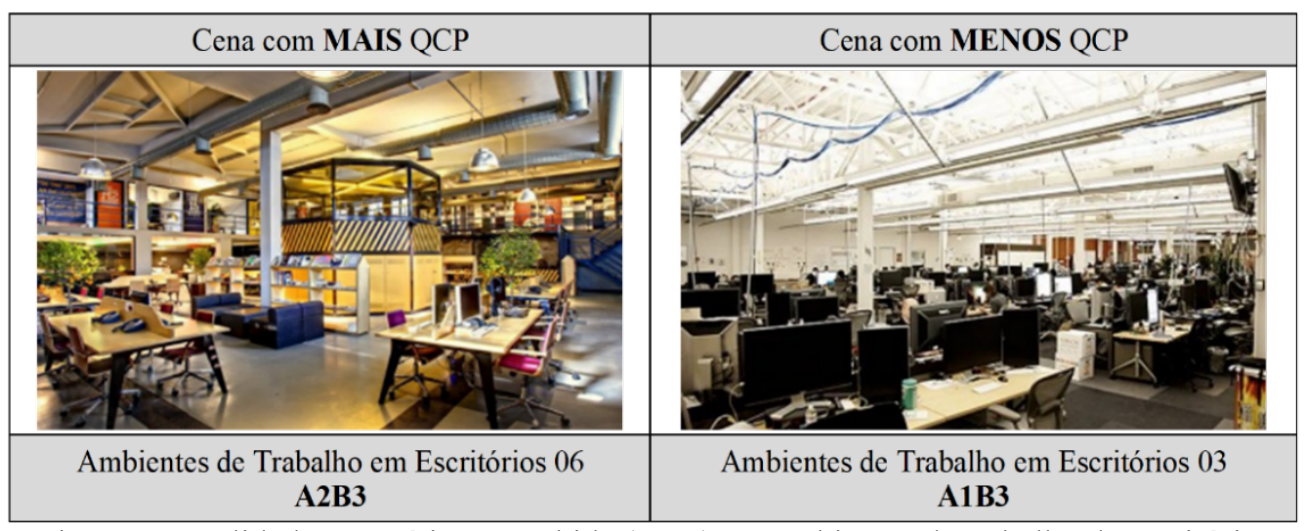

Figura 5: Qualidade Cromática Percebida (QCP) em ambientes de trabalho de escritório.

Os resultados revelam que ambas as facetas testadas, CONTRASTE e COMPLEXIDADE, mostraram-se aderentes para a avaliação proposta, além de que, o ambiente de trabalho de escritório com contraste médio (coerência média) e complexidade moderada tem mais qualidade cromática percebida, embora a teoria sugira isso para um ambiente com contraste baixo (coerência alta) e complexidade moderada. Logo, os achados desta pesquisa para o contraste (coerência) divergem do sugerido, mas corroboram-nos para a complexidade.

Isso significa que, em prol de diretrizes projetuais que auxiliem o planejamento da cor, um ambiente de trabalho de escritório com contraste cromático médio, associado com uma quantidade de elementos igualmente moderada e variada, favorece a Qualidade Cromática Percebida.

As avaliações empreendidas nesta pesquisa também buscaram analisar se havia consenso dos resultados expostos entre os dois grupos selecionados. Também, a partir dos diagramas da SSA, cada grupo foi inserido nas projeções do SSA para as Facetas de CONTRASTE e de COMPLEXIDADE como variáveis externas. Assim, os diagramas mostrados retratam, ao mesmo tempo, a estrutura regional e os diferentes grupos como variáveis externas, definidas pelos números 10 (especialistas) e 11 (não especialistas) (Figura 6).

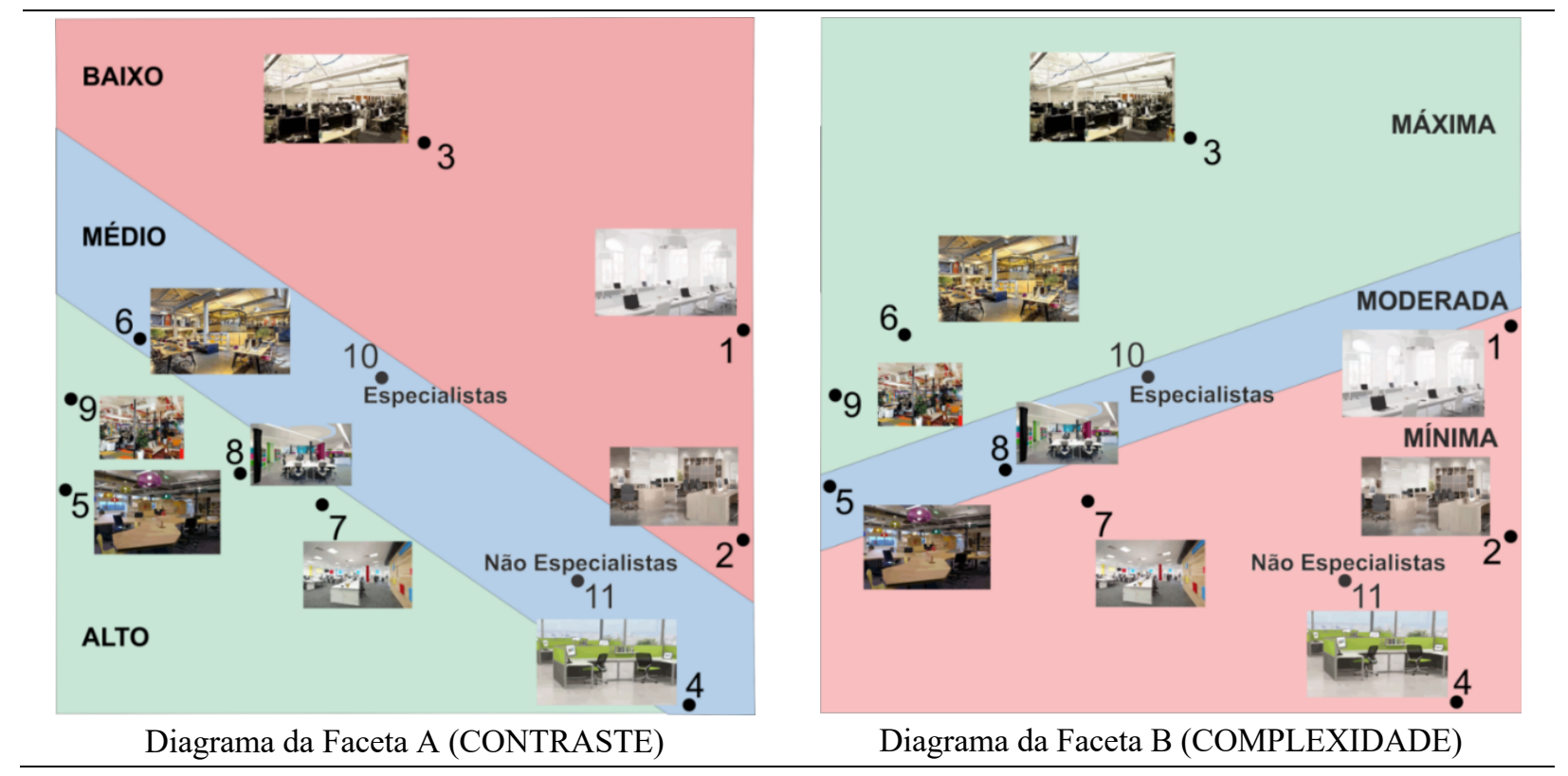

Figura 6 - Diagramas das Facetas (CONTRASTE - COMPLEXIDADE) com os dois diferentes grupos. 
Com base nas Figuras 6, o grupo de especialistas desta pesquisa, encontra-se na região de contraste médio (coerência média) e complexidade moderada. Já o grupo de não especialistas em projetos de ambientes, localizado na parte inferior direita dos diagramas, encontra-se nas áreas que reúnem ambientes de trabalho em escritório com contraste médio (coerência média) e complexidade mínima.

Através do exposto, e de modo específico, fica demonstrado que os especialistas abordados preferem um ambiente de trabalho de escritório com contraste médio (coerência média) e complexidade moderada; já os não especialistas em projetos de ambientes, uma cena com contraste médio (coerência média) e complexidade mínima. Segundo pôde ser verificado na matriz de correlação, a cena de maior correlação com o grupo de especialistas é aquela de número 6 , com contraste médio (coerência média) e complexidade máxima; enquanto para os não especialistas, foi a cena de número 4 , com contraste médio (coerência média) e complexidade mínima (Figura 6). Esse resultado é importante, pois mostra consenso entre os dois grupos para o contraste (coerência), mas divergência em relação à complexidade.

\section{Conclusão}

Inicialmente, é importante destacar que os principais resultados encontrados não podem ser considerados de uma maneira simplista, pois são específicos para o tipo de elemento de estímulo apresentado aos participantes abordados, a época e o local em que os dados obtidos foram coletados.

Buscando identificar se as características de coerência e de complexidade dos ambientes de trabalho de escritório eram aderentes à avaliação proposta, apurou-se que ambas se mostraram determinantes, já que formaram regiões de contiguidade entre seus elementos internos. Nessa perspectiva, a sentença estruturadora para a avaliação da Qualidade Cromática Percebida em ambientes de trabalho de escritório mostrou-se consistente para a avaliação, sendo desnecessário ser reescrita. Tal resultado, corrobora com uma das hipóteses desta pesquisa.

Ao examinar os efeitos das duas características de ambientes de trabalho de escritório tomadas para estudo, conclui-se que um ambiente com contraste médio (coerência média) e complexidade moderada tem mais Qualidade Cromática Percebida; enquanto outro, com contraste alto (coerência baixa) e complexidade máxima, como sugere a teoria apresentada nas considerações teóricas, representam o oposto.

Dentro dessa perspectiva, em prol de diretrizes projetuais que auxiliem o projeto cromático, um ambiente de trabalho de escritório com contraste cromático médio, associado com uma quantidade de elementos igualmente moderada e variada, favorece a Qualidade Cromática Percebida.

A partir do exposto, o objetivo geral desta pesquisa - avaliar a Qualidade Cromática Percebida em ambientes de trabalho de escritório - foi plenamente alcançado, e espera-se que essas diretrizes possam auxiliar as decisões nos projetos cromáticos de ambientes de trabalho em escritórios, na medida em que não deixaram para trás as análises empíricas, como orienta a Estética Ambiental e a Ergonomia do Ambiente Construído.

\section{Referências}

AMAR, R; TOLEDANO, S. HUDAP Manual. Jerusalem: The Hebrew University of Jerusalem Computing Center, 2005.

AMORIM, C. R. F. Imagem Avaliativa de Cenas de Frentes de Lojas dos Centros de Compras do Arranjo Produtivo Local de Confeç̧ões do Agreste de Pernambuco. 143f. Dissertação (Mestrado em Desenvolvimento Urbano), Programa de Pós-graduação em Design, Universidade Federal de Pernambuco, Recife, 2019. 
BERLYNE, D. E. Ends and meanings of experimental aesthetics. Canadian Journal of Psychology, 26, p. 303-325. 1972.

BINS Ely, V. Ergonomia + Arquitetura: buscando um melhor desempenho do ambiente físico. In: $3^{\circ}$ ERGODESIGN $-3^{\circ}$ CONGRESSO INTERNACIONAL DE ERGONOMIA E USABILIDADE DE INTERFACES HUMANO - TECNOLOGIA. 2003. Rio de Janeiro. Anais... Rio de Janeiro, LEUI/PUC Rio, 2003. p. 167-174.

BILKSY, W. A Teoria das Facetas: noções básicas. Estudos de Psicologia, v. 8, n. 3, p. 357-365. 2003.

BORG, I. Facet Theory. In: EVERITT, B.; HOWELL, D. (orgs.). Encyclopaedias of Statistics in Behavioral Science. 1. ed. Chichester: John Wiley \& Sons, Ltd, 2005. v. 2p. p. 595-599.

BORG, I; LINGOES, J. Multidimensional Similarity Structure Analysis. 1. ed. New York: SpringerVelarg New York Inc, 1987. 390 p.

CANTER, D.; BROWN, J.; GROAT, L. A multiple sorting procedure for studying conceptual systems. In BRENNER, M; BROWN, J.; CANTER, D. (Eds). The research interview: uses and approaches. London: Academic Press, 1985. p. 79-114.

COSTA, A. P. L.; ANDRETO, L.; VILLAROUCO, V. Avaliação de um espaço de trabalho a partir da metodologia de avaliação ergonômica do ambiente construído. In: MONT'ALVÃO, C., VILLAROUCO, V. (Org.). Um novo olhar para o projeto: a ergonomia do ambiente construído. 1ed.Teresopolis: $2 \mathrm{AB}$ Editora Ltda, 2011, v. 1, p. 95-113.

COSTA FILHO, L. L. MIDIÁPOLIS: Comunicação, Persuasão e Sedução da Paisagem Urbana Midiática. 272f. Tese (Doutorado em Desenvolvimento Urbano), Programa de Pós-graduação em Desenvolvimento Urbano, Universidade Federal de Pernambuco, Recife, 2012.

\section{O enfoque da teoria das facetas na avaliação de lugares. In: V ENEAC - ENCONTRO}

NACIONAL DE ERGONOMIA DO AMBIENTE CONSTRUIIDO E VI SEMINÁRIO NACIONAL DE ACESSIBILIDADE INTEGRAL, 2014. Rio de Janeiro. Anais... Rio de Janeiro, PUC- Rio, LEUI/PUC Rio. 2014.

COSTA FILHO, L.; OLIVEIRA, I. F.; YOKOYAMA, S. A. A qualidade percebida em cenas do comércio varejista do centro de caruaru. In: VI ENEAC - ENCONTRO NACIONAL DE ERGONOMIA DO AMBIENTE CONSTRUIIDO E VII SEMINÁRIO NACIONAL DE ACESSIBILIDADE INTEGRAL, 2016. Recife. Anais... Recife, UFPE, 2016. p. 541-552

FERNANDES, M; COSTA FILHO, L. A qualidade cromática percebida em escritórios. In: VI ENEAC ENCONTRO NACIONAL DE ERGONOMIA DO AMBIENTE CONSTRUÍDO E VII SEMINÁRIO NACIONAL DE ACESSIBILIDADE INTEGRAL, 2016. Fortaleza. Anais... Fortaleza, UFC, 2018.

FIGUEIREDO, J.; MONT'ALVÃO, C. Cor nos locais de trabalho: como aplicá-la de forma adequada às necessidades dos usuários e às exigências da tarefa. In: XIV CONGRESSO BRASILEIRO DE ERGONOMIA, n. 14, 7f, out/nov. 2006. Curitiba. Anais... Curitiba, ABERGO, 2006.

. A ergonomia ambiental no processo de composição cromática de locais de trabalho de escritório. In: MORAES, A. (Org.). Ergodesign do ambiente construído e habitado: ambiente urbano, ambiente público, ambiente laboral. Rio de Janeiro: iUsEr, 2004. p109-134. 
GIBSON, J. The ecological approach to visual perception. Boston: Houghton Mifflin, 1979.

KAPLAN, S.; KAPLAN, R. Cognition and environment: functioning in an uncertain world. New York: Praeger, 1982.

MAHNKE, F. Color, environment \& human response: an interdisciplinary understanding of color and its use as a beneficial element in the design of the architectural environment. 1. Ed. New York: John Wiley \& Sons, 1996.

MARCONI, M. A; LAKATOS, E. M. Técnicas de pesquisa: planejamento e execução de pesquisas, amostragens e técnicas de pesquisa, elaboração, análise e interpretação de dados. São Paulo: Atlas, 2009.

MONTEIRO, C. M. G.; ROAZZI, A. Polemic images: Dwellers' concepts of life in historic areas. In: COHEN, A. (Ed.). Facet Theory and scaling: in search of structure in behavioral and social sciences. Israel: Rubin R. I. D, 2009. p. 99-109.

NASAR, J. L. Visual quality by design. 1. ed. Washington, D.C: Haworth Inc, 2008.

The evaluative image of places. In: WALSH, W. B.; CRAIK, K. H.; PRINCE, R. H.

2nd. ed. (Eds.). Person-environment psychology: new directions and perspectives. New Jersey: Lawrence Erlbaum Associates, 2000. p. 117-168.

The effect of sign complexity and coherence on the perceived quality of retail scenes. In: NASAR, J. L. (Ed.). Environmental Aesthetics: theory, research, \& applications. New York: Cambridge University Press, 1988. p. 300-320.

OLIVEIRA, C. K. Procedimento conceitual para avaliação de ambientes de Coworking: a qualidade visual percebida no novo padrão de Escritório. 146f. Dissertação (Mestrado em Desenvolvimento Urbano), Programa de Pós-graduação em Design, Universidade Federal de Pernambuco, Recife, 2019.

ÖZTÜRK, E. The effects of color scheme on the appraisal of an office environment and task performance. $145 \mathrm{f}$, These (Master of Fine Arts). Bilkent University, Ankara, 2010.

ROAZZI, A; MONTEIRO, C. M. G; RULLO, G. Residencial satisfaction and place attachment: A crosscultural investigation. In COHEN, A. (Ed). Facet Theory and Scaling: In search of structure in behavioral and social sciences. Israel: Rubin R. I. D, 2009. p. 81-97.

SAVAVIBOOL, N. The Effects of Colour in Work Environment: A systematic review. EnvironmentBehaviour Proceedings Journal, v. 1, n. 4, p. 262, 2016.

SHYE, S.; ELIZUR, D.; HOFFMAN, M. Introduction to Facet Theory: Content design and intrinsic data analysis in behavioral research. London: Sage, 1994.

SILVA JÚNIOR, J. A. Qualidade visual percebida de vitrines. 272f. Dissertação (Mestrado em Design), Programa de Pós-graduação em Design, Universidade Federal de Pernambuco, Recife, 2017.

STAMPS, A. E. Perceptual and preferential effects of photomontage simulations of environments. In: Perceptual and Motor Skills, n ${ }^{\mathbf{0}}$ 74, 1992.

VILLAROUCO, V. Tratando de ambientes ergonomicamente adequados: seriam ergoambientes? In: Mont'Alvão, C.; Villarouco, V. (Org.). Um novo olhar para o projeto: a ergonomia no ambiente construído. 1ed. Teresópolis, RJ: 2AB, 2011, v. 1, p. 25-46. 
. Reflexão sobre a ergonomia aplicada aos ambientes construídos e caminhos percorridos. In: Mont'Alvão, C.; Villarouco, V. (Org.). Um novo olhar para o projeto 4: a ergonomia no ambiente construído. 4ed. Olinda: Livro Rápido, 2018, v. 4, p. 11-24.

WOHWILL, J. F. Environmental aesthetics: The environment as a source of affect. In: ALTMANN, I.; WOHWILL, J. F. (Eds.), Human Behaviour and Environment, V. 1, p 37-86, 1976.

\section{Agradecimento}

Os autores deste trabalho agradecem ao CNPq (Conselho Nacional de Desenvolvimento Científico e Tecnológico) pelo apoio recebido, vindo através de uma Bolsa de Mestrado, bem como aos voluntários. 